Coast and Sierra Leone, and one of their most important functions will be to teach technical and commercial subjects up to professional level and to increase facilities for teacher training.

Technical education at the lower levels is, in fact, receiving increasing attention everywhere in the territories: in Uganda the main educational effort is towards schools of a less academic type; the junior technical schools in Malaya are filled to capacity, while a course in architecture has been added at the Technical College in Kuala Lumpur, and building for a new technical college is about to commence.

All these developments involve demands on the Colonial universities and university colleges and affect their work as well as the prospects for their students. But while the Inter-University Council has clearly been considering a wide range of problems as well as the factual developments recorded in this report, it scarcely touches on some fundamental issues concerning the position of university institutions in Colonial society. Satisfied that adequate academic standards of work have been attained and are likely to be maintained, the Council does indeed recognize that it is now becoming important to ensure that the most effective use is made of the services of students trained in such institutions, from the point of view of the students themselves and of their peoples. But it contents itself with expressing the hope that too high a proportion of the graduates will not be absorbed into government service, because of the importance of introducing some of this sure experience and trained ability into other sectors of society, such as journalism, commerce and industry.

The future of the Colonial universities does not depend solely on their ability to maintain high academic standards: it depends equally on their ability to provide the societies which they exist to serve with trained men and women who can meet the needs of these societies and fit happily into their way of life. If there is no place in such societies for the men and women coming from the new university institutions, no opportunity for the utilization of their technical or professional ability, and no adequate or satisfying cultural life, those institutions will themselves ultimately decay. The absorption of trained man- and woman-power into the Colonial life of to-day involves difficult and interesting problems, and the Inter-University Council could appropriately have used its annual report to discuss one or two such topics, particularly those bearing on the relationship between university education and secondary or primary education.

\section{CURRENT TRENDS IN SOCIAL PSYCHOLOGY}

$\Delta \mathrm{T}$ the recent Edinburgh meeting of the British A Association, Section J (Psychology) devoted each of its fivo mornings to current trends in psychology, and in one session, "Current Trends in Social Psychology", four papers were presented which had many interlocking features. The first, by Dr. H. J. Eysenck, described researches into social attitudes. He held that popular newspaper polls of public opinion, the Gallup and similar polls, though interesting, are of little scientific value. Newspaper polls ask broad, general questions, and do not take sufficient account of the political affiliations of people questioned. Investigation into attitudes towards different issues of present-day importance show a great tendency for certain attitudes to cluster together in a manner characteristic of Radicals and Conservatives.

Dr. Eysenck propounded a distinction between what he calls "tough-minded" and "tender-minded" persons. (It is perhaps unfortunate that this distinction, well known in psychology since the late Prof. William James first used these terms, has been accepted by psychologists as meaning something different, but not entirely different, from Dr. Eysenck's new use of the term.) He contrasted the moral approach of the tender-minded, who are idealistic, ethical, religious and to whom the individual is sacrosanct, and the tough-minded, who believe in the inferiority of coloured people, Jews and women, and in the 'inevitability' of war. The working-class person, he said, is on the average very much more tough-minded and conservative than the average middle-class person. $\mathrm{H}_{\Theta}$ described recent investigations into the organization of attitudes, their relation to political-party membership, age, sex, education, social class, and personality, and also into the effect upon the structure of attitudes of differences in culture-pattern.

The second paper, on "Personality Tests as Research Tools", by Dr. Hilde T. Himmelweit, considered 'objective' tests that require the subject to perform sonie task under standard conditions, the response to which can be objectively measured. Examples of these tests are of motor co-ordination, speed and accuracy of response, suggestibility, persistence, levels of aspiration and expressive movement. Though the behaviour involved in these may throw light on deeper mental levels, such tests do not tap these levels as specifically as projection tests do, and yet the results of objective tests are unaffected by the psychologist's subjective interpretation of the responses.

The use of batteries of objective tests makes possible the investigation of entirely new problems. One concerns the relationship between normal, neurotic and psychotic states. Kretschmer has maintained that these conditions differ from each other only quantitatively, not qualitatively, and can be viewed as lying along the same continuum with schizophrenia and manic-depressive psychosis. Eysenck, using a wide range of objective personality tests, has found that, on most tests, the patterning or inter-correlations of the test result was sufficiently similar in the normal and psychotic groups to support strongly Kretschmer's hypothesis. Objective tests are also useful in studying the effect upon the personality of leucotomy. Azenath Petrie has given tests to patients before and at stated intervals after this operation. The results enabled her to describe the characteristics of the postleucotomy personality.

Objective tests will be used in a research, being carried out at the London School of Economics, into the differences in attitude to personality characteristics of young adolescents from different social classes. They will test the hypothesis proposed by Davis, of Chicago, that middle-class parents cherish higher aspirations for their children than working. class parents, that the child tends to introject the parents' demands and to react by having higher aspirations and being anxious regarding their attainment. It is proposed to find the extent to which middle-class children, compared with children from 
other classes, give significantly higher scores on tests of 'level of aspiration' and of anxiety.

The next speaker, Dr. A. T. M. Wilson, discussed "Social Changes in Structured Groups", a group being termed structured when it contains a manifest system of inter-related roles. The study of social processes in real (that is, not artificially created) situations, in terms of the psychological and social forces concerned, raises problems connected with the possibility of obtaining access to the group for the purpose of direct observation. There may be resist. ance or reluctance to proposals that the social investigator should be admitted to a 'reality situation', and this raises questions concerning the role of a participant observer in a community particularly susceptible to social change. If in a structured group need is felt for help in bringing about desired change, this need will provide one set of circumstances facilitating access by the investigator. A research worker, responding to a request for technical collaboration, in tackling a group problem, may assume a role the existence and independence of which are derived from its responsible professional character. The use of such roles may facilitate social change, since insight, derived from observations equally available to the group concerned and to the research worker, can be mutually communicated. The scope and limitations of such an approach were illustrated in detail from the work of one industrial organization which employs it.

Prof. T. H. Pear discussed "The Social Psychology of Everyday Life". This paper's title, borrowed with grateful acknowledgment, is that of a well-known article by Prof. Hadley Cantril, of Princeton University ${ }^{1}$. Written seventeen years ago, it urged that really important events in the lives of ordinary people had seldom been studied by psychologists.

To-day, one can report a considerable increase in the social significance of the subjects studied. The development of techniques for investigating attitudes and public opinion and for interviewing (for example, in vocational guidance, medicine and anthropology), the study of likenesses and differences in national characteristics and the effect of social factors upon test performances, the intensive study of patterns of culture and tensions between communities ${ }^{2}$, all these events and more testify to a considerable change in the climate of opinion. The ordinary man in his social setting here and now is gradually if slowly becoming an object of scientific interest.

There are still important subjects which have received relatively little attention from social psychologists. Of these the most obvious are peace and war, since to-day almost all problems of planning are affected by the possibility of another war. Another neglected subject in Britain is social stratification. To the study of these subjects there certainly exist strong resistances; to discover and account for them is an interesting task for the social psychology of the future.

Prof. Pear's paper suggested that discovering the causes of this oversight is an interesting psychological project. Consider differences in classes, strata and élites. Much has been written about inferiority complexes ${ }^{3}$, and our knowledge in this realm would be enriched by introspective accounts of how it feels to find oneself in such 'natural' situations of superiority or inferiority, and of the modifications of behaviour which one deliberately produces to adjust oneself. Partly conscious, partly unconscious factors may cause the widespread lack of interest among psychologists in problems of peace and war and of social stratification. It is time to realize frankly that in many people there are conscious reasons for not objecting to war. Unconscious reasons exist too; but they have had a good Press for the past three decades, and more research into the conscious reasons is needed. It is time for students of society to direct public attention less to the differences between peoples and much more to their resemblances, even if this decreases the 'noveltyrarity' value of their books and lectures.

During the meeting a demonstration was given of a film-gramophone technique, devised by Davide Boulting, C. E. M. Hansel and Prof. Pear, to investigate impressions of personality, vocation and social stratum from voice and facial appearance. While a voice spoke a prescribed passage designed to bring out geographical or social 'accents', pictured 'back. grounds', both physical and social, and faces were projected on the screen. In the experiments to be carried out, subjects will attempt to match these with the voices.

${ }^{1}$ Psychol. Bull., 297 (1934).

" cf. Klineberg, otto, "Tensions Affecting International Understanding", Bull. 62, Social Science Research Council, New York, $17(1950)$.

${ }^{3} \mathrm{cf}$. Brachfleld, Oliver, "Inferiority Feelings" (London: Routledge and Kegan Paul, 1951).

\section{RECENT DEVELOPMENTS AND TECHNIQUES IN THE MAINTENANCE OF STANDARDS}

AWO-DAY symposium was held at the National A Physical Laboratory during May 21 and 22 on "Recent Developments and Techniques in the Maintenance of Standards". Most of the standardizing laboratories of Europe, the Commonwealth and North America were represented, and delegates attended frorn many research organizations and industrial firms in Great Britain. Dr. E. C. Bullard, director of the Laboratory, in opening the symposium, remarked that it had every chance of being a successful occasion since there was no official business of any kind and no one need come to any conclusions. Sir Ben Lockspeiser, secretary of the Department of Scientific and Industrial Research, was among the audience and added his welcome to Dr. Bullard's.

Dr. D. G. Sopwith, superintendent of the Engineering Division of the Laboratory, took the chair for the first session, on "Primary Load Standards". The first paper was presented by Mr. B. L. Wilson, head of the Engineering Mechanics Section of the National Bureau of Standards, Washington. He gave a very interesting summary of the various dead-weight machines belonging to the Bureau and the types of devices calibrated in them. Dr. F. Aughtio (National Physical Laboratory) followed this with a paper on "The Primary Load Stand"ard" in which he described the 50-ton dead-weight standard at the National Physical Laboratory and spoke of the adjustment of it to 'standard' gravity $(980.665 \mathrm{~cm}$./ sec.), which was about to be undertaken. He described also the Laboratory's 5-ton standard for the calibration of small proving rings, and experiments with resistancestrain gauges on compression elements for loads greater than 50 tons.

The second session was concerned with "The Standard of Length", and Mr. F. H. Rolt, super- 